\title{
Occupational Hazards and Safety Nursing Guidelines for Pediatric Nurses in the Health Care Setting
}

\author{
Amal Ahmed Elbilgahy' ${ }^{1}$ Shereen Ahmed Elwasefy ${ }^{2}$ \& Magda Ahmed Abd El Aziz ${ }^{3}$ \\ 1,2,3 Lecturers of Pediatric Nursing, Faculty of Nursing, Mansoura University, Egypt \\ Correspondence author: amal ahmed568@yahoo.com
}

\begin{abstract}
:-
Safety in the workplace was the major concern in a variety of occupations and workplace settings. In nursing, the main concern of research was concerned on patient safety; there was limited researches focused on nurses' safety in work setting. Therefore, the aim of this study was to evaluate the effect of implementing occupational hazards and safety nursing guidelines for pediatric nurses in the health care setting. A quasiexperimental research design using one group (pre-test \& post-test measures) was used. A convenience sample of 173 pediatric nurses affiliated to Mansoura University children's Hospital (MUCH), Mansoura University, Egypt; and accepted to participate in the study was included. The study illustrated that, $77.9 \%$ of nurses suffered from fatigue, $69.5 \%$ of nurses had back pain. In addition, significant number of nurses are exposed to MRSA infection $(61.7 \%)$ and $67.4 \%$ are exposed to needle stick injury. Before implementing the nursing guidelines, approximately half of nurses had low level knowledge (46.8\%) compared to $15 \%$ after implementation of nursing guidelines $\&$ the difference was statistically significant. The study concluded that, the hazards associated with nursing profession were higher and critical. In addition, there was an improvement of nurse's knowledge and practice about safety with the implementation of educational guidelines. Therefore, the researchers' recommended developing standard of health care safety clarifying the role of health care institution in dealing with and overcoming the occupational hazards in the health care setting in order to improve nurses' safety and commitment to the health care environment.
\end{abstract}

Key words: nurses safety, occupational hazard, nursing guidelines \& occupational hazards prevention DOI: $10.7176 / \mathrm{JHMN} / 59-10$

\section{Introduction:}

Nursing is a profession within the health care sector focused on the care of individuals, families and communities; so, they must attain, or recover optimal health and quality of life (Awan et al., 2017 and Doyle, 2017). Nurses are the largest group of healthcare workers in medical profession and experience a higher rate of workplace hazards exposure than other health care workers because nurses assist and perform more bedside procedures (Rhule, 2012). Nurses are at greater risk of injuries and occupational hazards due to their job activities in the health care setting (Isara and Ofili, 2012).

Healthcare organizations are characterized by multidimensional and complex environments that make nurses prone to occupational hazards and injuries. Beside the nature of nurses working environment, duties and responsibilities, nurses are facing numerous occupational hazards such as chemical, biological, environmental, physical and psychological risks (Isara and Ofili, 2012, Anandh et al. 2015). According to World Health Organization, workplace hazards are the $10^{\text {th }}$ leading cause of diseases and death at the workplace (Faremi, et al., 2014).

Exposures to occupational hazards throughout hospital departments are highly variable. Chemical exposures can occur from disinfectants, cleaning compounds, hazardous drugs, mercury, and anesthetic gases. Biological hazards include viruses and bacteria, which cause hepatitis B and C, HIV, and tuberculosis, as well as latex allergy. Physical hazards are workplace agents that can cause tissue damage by transfer of energy from the agent (e.g., noise, radiation). Physical hazards include ionizing and non-ionizing radiation and ergonomic injuries from patient lifting and handling, lifting heavy equipment cause backache, and static postures (Rhule, 2012 and Rogers, 2003). Furthermore, psychological and work organization stressors including shift work, burnout, and workplace violence may effect on clinical practice (Gorman, et al., 2014). Also, Nurses quality of life and quality of care for the pediatric patients may affect more due to the occupational stress (Sarafis, et al., 2016).

The principle of 'do no harm' is a cornerstone of care. Patient safety and nurses' safety must complement each other; one does not override the other. Importantly, a task is not safe unless it is safe for everyone engaged in or affected by the task; this includes the patient and all health care workers (Work Health and Safety Essentials for Nurses and Midwives. 2013). 
The multiplying effects of injuries and diseases among nurses include economic loss, physical loss and psychological disorders such as depression and stress. Consequently, these have negative effect on the nurses, their families and the nation at large (Adelosoye et al., 2016). Nurses and other healthcare providers should receive training and education on ways of prevention of hazards in the hospital to protect their health (Smith, 2009). Safety in the hospital care setting means the presence of measures that minimize the risk of physical, biological, chemical and psychological harm. These can be achieved for example; safe patient handling and mobility practices and reasonable patient care assignments, and shift duration (Zolot, 2017). Nurses' constitute a large group of health care team; they are working with the patients and their family and they are exposed to different type of health risk during their work. Therefore, controlling and minimizing workplace hazards represent a unique challenge.

\section{Significance of the problem:}

Hospitals have many unique hazards that can potentially affect the health of employees. Exposures to occupational hazards throughout hospital departments are highly variable (Gorman, et al., 2014). Due to the importance of hospital safety, it is not surprising that a lot of research have been applied to this topic. There is no previous study was conducted on pediatric nurses in Mansoura University Children's Hospital on that area. Hence, this study was conducted to evaluate the effect of implementing occupational hazards and safety nursing guidelines for pediatric nurses in the health care setting

\section{Subjects and methods \\ Aim of the study:}

This study aimed to evaluate the effect of implementing occupational hazards and safety nursing guidelines for pediatric nurses in the health care setting. This aim can be achieved through:-

1. Assessment of actual physical, emotional, psychological and biological hazard as reported by nurses

2. Assessment of nurses perception about safety in hospital care setting

3. Assessment of nurses' knowledge and practice about safety measures of hospital care setting

4. Developing and implementing training program for nurses about safety in the work setting and hazard prevention

5. Evaluating the effect of training program on nurses knowledge and practice

\section{Research hypothesis:}

- Nurses who attend the occupational hazards and safety nursing guidelines have good knowledge and practice about safety in the hospital.

- Nurses' knowledge and practices will improve after implementing the occupational hazards and safety nursing guidelines.

\section{Study Design \& Setting}

A quasi-experimental research design using one group (pre-test \& post-test measures) was used. The study included a convenient sample of 173 pediatric nurses who accepted to participate in the study. The study was conducted on eight departments including (Medical, Surgical, Operating room, Pediatric intensive care unit, Neonatal intensive care unit, Outpatient, Dialysis unit and Emergency) affiliated to Mansoura University children's Hospital (MUCH), Mansoura University; Egypt. Instruments:-

Data were collected by using two tools: occupational hazard assessment questionnaire and occupational hazards prevention and safety checklist which were developed by the researchers after reviewing related literature (Osborne, 2002, Gao, 2011) and incorporated four parts. 1) Demographic characteristics of the studied nurses, 2) occupational hazard assessment questionnaire, 3) actual hazards facing nurses during their working in the hospital, 4) pediatric nurses' perception of safety in health care environment. Part 1: Demographic characteristics of the studied nurses include age, gender, marital status, residence, qualification, years of experience, department and attendance of any training regarding occupational hazard and safety measures. Occupational hazard assessment questionnaire was developed to evaluate nurses' knowledge about occupational hazard; it was consisted of 13 item related to contributing factors, prevention of hazards, needle stick injury and blood borne disease.

The third part of the questionnaire was developed to evaluate the actual hazards facing nurses during their working period in the hospital. This part was including 51 items categorized into four domains (physical hazard, chemical, social \& emotional hazard) the nurses were respond with "yes" or "no" for every question. In the fourth part of questionnaire, the nurses were asked about their perception of safety in health care environment; it was incorporated 10 statements. The nurses responds to each item using 3 point likert scale: (3) strongly agree, (2) agree \& (1) not agree. 
Tool (2) occupational hazards prevention and safety checklist was used to evaluate the pediatric nurses' practice related to prevention of occupational hazards and observe nurses practice during handling of sharp equipment, prevention of blood-borne disease and infection control practice. Each correct step of the procedure scored on the bases of "complete correct done" scored (2), \& "Not done", scored (0). The nurses were considered had competent practice if the percent score was $80 \%$ or higher and incompetent practice if the percent score was less than $70 \%$.

\section{Validity and reliability}

The validity and reliability of the developed tools was done. These tools were revised by a panel of 10 experts in pediatric and community health nursing and medicine at Mansoura University. Minor modification was done on the tools. Tools reliability were done using Alpha Cronbach's coefficient test, the alpha reliability of tool 1 was $(\alpha=0.83)$, while, reliability of tool 2 was $(\alpha=0.90)$.

\section{Workplace hazards prevention \& safety nursing guidelines}

Workplace hazards prevention \& safety nursing guidelines was developed the researchers based upon recent, current, national, and international literature \& updated articles and evidence based nursing practice (Registered Nurses' Association of Ontario, 2008; Tung et al., 2014 and Gorman et al., 2014). The nursing guidelines were discussed for nurses on six sessions divided into two theoretical \& four practical sessions. The time consumed for each session was ranged from 30-45 minutes. The nurses were assigned to groups ten (10) nurses in each group. The researchers were represented the nursing guidelines via using Power point, lectures, brain storming, and clinical application. In addition, posters and educational book were used and available in the units for every nurse. The nursing guidelines cover the following outline about hazards prevention $\&$ safety such as: Purposes of occupational health, occupational hazards types, causes, and preventive methods, infection control universal precautions, prevention of needle stick injuries, prevention of transmission of blood born $\&$ infectious disease, stress and its management $\&$ standard safety precautions.

\section{Ethical Considerations}

Ethical authorization was gained from "Research Ethics Committee at the Faculty of Nursing, Mansoura University". Agreement to carry out the study was obtained from the principal of the hospital after explaining and clarifying the aim of the study. Written consent was obtained from nurses after amplification of the aim of the study. Privacy of information and nurses right to depart the study whenever was disclosed to each mother before collecting data.

\section{Data collection}

The data was collected from February to the end of December, 2016; the questionnaire was distributed to all nurses working in the previously mentioned departments and collected by the researchers representing response rate of $69.2 \%$.

\section{Pilot study}

A pilot study was carried out on 17 nurses to ascertain the feasibility, applicability and clarity of the tool and there is no modification required.

\section{Data Analysis}

Data were analyzed with SPSS version 21. The normality of data was first tested with one-sample Kolmogorov-Smirnov test. Qualitative data were described using number and percent. Continuous variables were presented as mean $\pm \mathrm{SD}$ (standard deviation) for parametric data and Median for non-parametric data. The two groups were compared with Student $t$ test (parametric data). The level of significance for all testes was at $\mathrm{p}<0.05$. 


\section{Results:-}

Table (1); Socio-demographic characteristics of the studied nurses

\begin{tabular}{|c|c|c|}
\hline Variables & No (173) & $\%$ \\
\hline \multicolumn{3}{|l|}{ Age years } \\
\hline $19-29$ & 67 & 38.7 \\
\hline $30-39$ & 58 & 33.5 \\
\hline $40-49$ & 29 & 16.8 \\
\hline 50\& more & 19 & 11.0 \\
\hline \multicolumn{3}{|l|}{ Gender } \\
\hline Male & 16 & 9.2 \\
\hline Females & 157 & 90.8 \\
\hline \multicolumn{3}{|l|}{ Residence } \\
\hline Rural & 125 & 72.3 \\
\hline Urban & 48 & 27.7 \\
\hline \multicolumn{3}{|l|}{ Marital status } \\
\hline Single & 20 & 11.6 \\
\hline Widow & 8 & 4.6 \\
\hline Married & 143 & 82.7 \\
\hline Divorced & 2 & 1.1 \\
\hline \multicolumn{3}{|l|}{ Qualification } \\
\hline Nursing diploma & 63 & 36.4 \\
\hline Technical institute of nursing & 32 & 18.5 \\
\hline BSc nursing & 78 & 45.1 \\
\hline \multicolumn{3}{|l|}{ Years of experience } \\
\hline $1-5$ year & 43 & 24.8 \\
\hline 6-10 & 52 & 30.1 \\
\hline $11-15$ & 45 & 26.0 \\
\hline $16 \&$ more & 33 & 19.1 \\
\hline \multicolumn{3}{|l|}{ Department } \\
\hline Outpatient & 12 & 6.4 \\
\hline Surgery & 10 & 1.2 \\
\hline Operating Room (OR) & 18 & 10.4 \\
\hline Medical Word & 14 & 8.1 \\
\hline Pediatric Intensive Care Unit (PICU) & 36 & 20.8 \\
\hline Dialysis & 28 & 16.2 \\
\hline Neonatal Intensive Care Unit (NICU) & 42 & 24.3 \\
\hline Emergency & 13 & 7.5 \\
\hline \multicolumn{3}{|l|}{ Attendance of training program } \\
\hline Yes & 78 & 45.1 \\
\hline No & 95 & 54.9 \\
\hline
\end{tabular}

Socio-demographic characteristics of the studied nurses were illustrated in Table (1); it was clear that, more than one third of the nurses (38.7\%) were in the age group from 19 to 29 years, while minority of them $(11.0 \%)$ had 50 years and more. It was also apparent that, the majority of them was females \& married $(90.8 \%$ \& $82.7 \%$ respectively). Regarding the educational level, this table revealed that, the highest percentage of the nurses $(45.1 \%)$ had bachelor degree in nursing. In addition, one third (30.1\%) of studied nurses' had from 6-10 years of experiences. It was also evident that $(54.9 \%)$ of the nurses did not attain any previous training courses related to workplace hazards. As regards most workplace department $(24.3 \%, 20.8 \%$, and $16.2 \%)$ of them were found in NICU, PICU and dialysis respectively. 
Figure 1; Nurses' self-report of physical hazards exposure

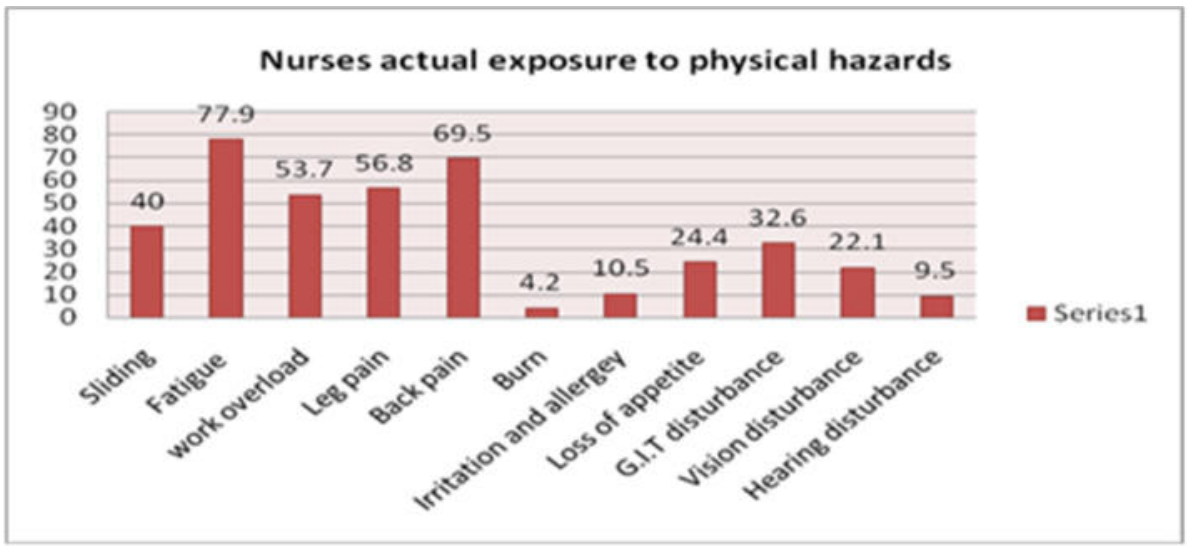

Figure (1) illustrated nurses' self-report of physical hazards exposure; more than two thirds of the studied nurses had complain from fatigue, back pain and leg pain $(77.9 \%, 69.5 \%$, and $56.8 \%$ respectively). It was also apparent that, $53.7 \%$ of the nurses had work overloaded.

\section{Figure 2; Nurses' self-report of social \& emotional hazards exposure}

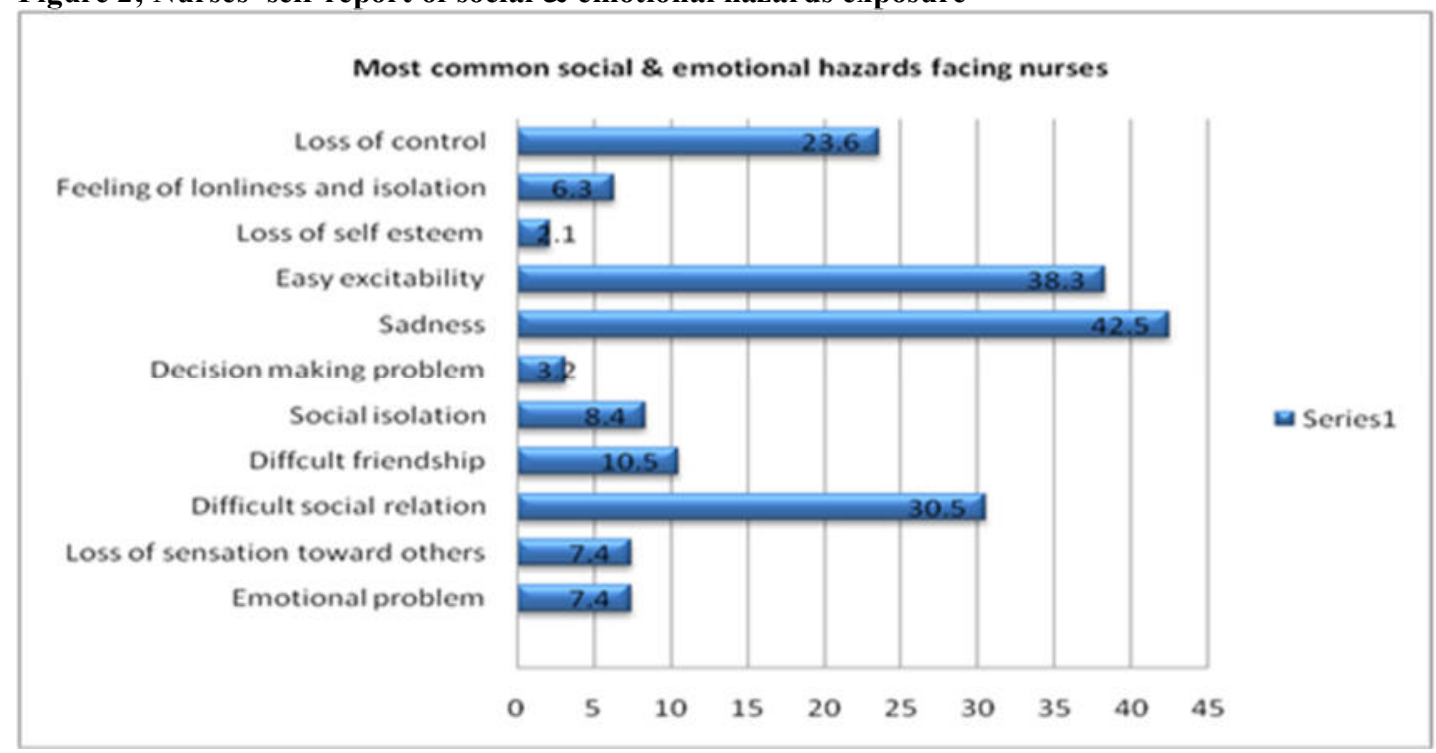

Figure (2): Concerning the nurses' self-report of social \& emotional hazards exposure. This figure revealed that, more than one third had exposed to sadness and easy excitability $(42.5 \% \& 38.3 \%)$. Also, $30.5 \%$ of them had difficulties in social relation. 


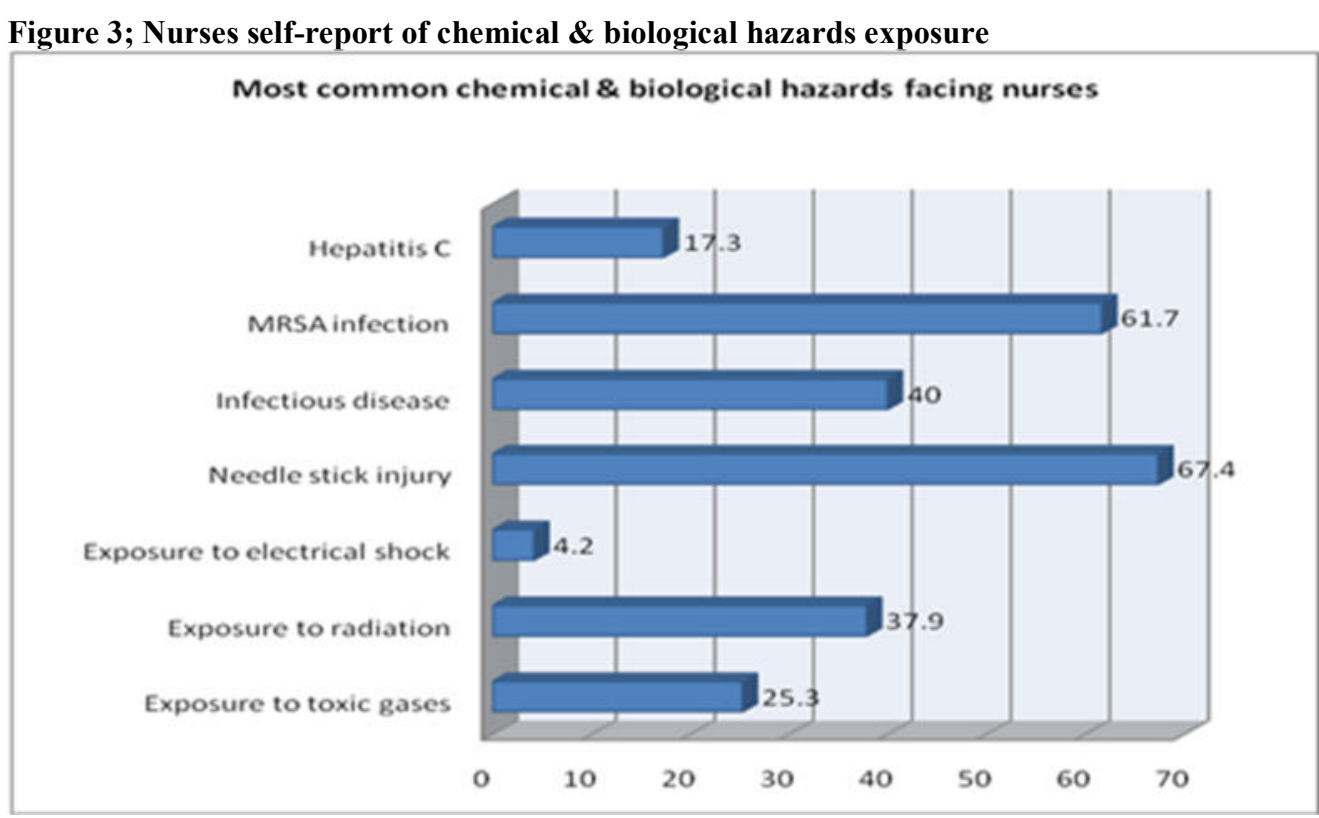

Figure (3): Regarding nurses self-report of chemical \& biological hazards exposure. This figure clarifies that, more than two third (67.4\%) of them had exposed to needle stick injury. Also, infectious biological hazards observed as MRSA infection, infectious diseases and hepatitis $\mathrm{C}$ by percentage of $61.7 \%, 40 \%$ and $17.3 \%$ of the nurses respectively.

Table (2); Nurses' knowledge about predisposing factor and preventive measures for occupational hazards in the hospital

\begin{tabular}{|l|c|c|}
\hline \multicolumn{1}{|c|}{ Predisposing factor * } & $\begin{array}{c}\text { Frequency } \\
\text { (NO 173) }\end{array}$ & $\begin{array}{c}\text { Percentage } \\
\text { (\%) }\end{array}$ \\
\hline Lack of equipment and supplies for protection & 95 & 54.9 \\
\hline lack of lifting tools and transportation of patients & 145 & 83.8 \\
\hline Shortage of nursing staff & 121 & 69.9 \\
\hline Work overload and standing for long period of time & 167 & 96.5 \\
\hline Lifting heavy objects (patients \& equipment) & 98 & 56.6 \\
\hline Lack of safety measures policy \& procedures in the hospital & 87 & 50.3 \\
\hline Lack of regular medical examination \& vaccination for all health care worker & 34 & 19.6 \\
\hline Inadequate training about workplace hazard \& its prevention & 127 & 73.4 \\
\hline Preventive measures for hazards in the hospital* & 143 & 82.6 \\
\hline Appropriate training for nurses on safety procedures & 132 & 76.3 \\
\hline Avoid standing for long periods & 94 & 54.3 \\
\hline $\begin{array}{l}\text { Strict adherence to the rules of safety, protection and special regulations } \\
\text { within the hospital }\end{array}$ & & \\
\hline Avoid lifting heavy equipment & 121 & 69.9 \\
\hline Adherence to hand washing practice & 89 & 51.4 \\
\hline Using personal protective tools & 113 & 65.3 \\
\hline
\end{tabular}

* Categories are not mutually exclusive

Table (2) nurses' knowledge about predisposing factors \& preventive measures for hazards in the hospital; this table showed that, the majority of the nurses were replied that work overload and standing for long period of time and lack of lifting tools and transportation of patients were the most common risk factor for hazards $(96.9 \%$ and $83.8 \%$ respectively). Moreover, $82.6 \%$ of nurses were reported that appropriate training for nurses on safety procedures was the most common preventive measures for hazards in the hospital. 
Table (3); level of nurses' knowledge and practice about safety measures in environmental health care setting

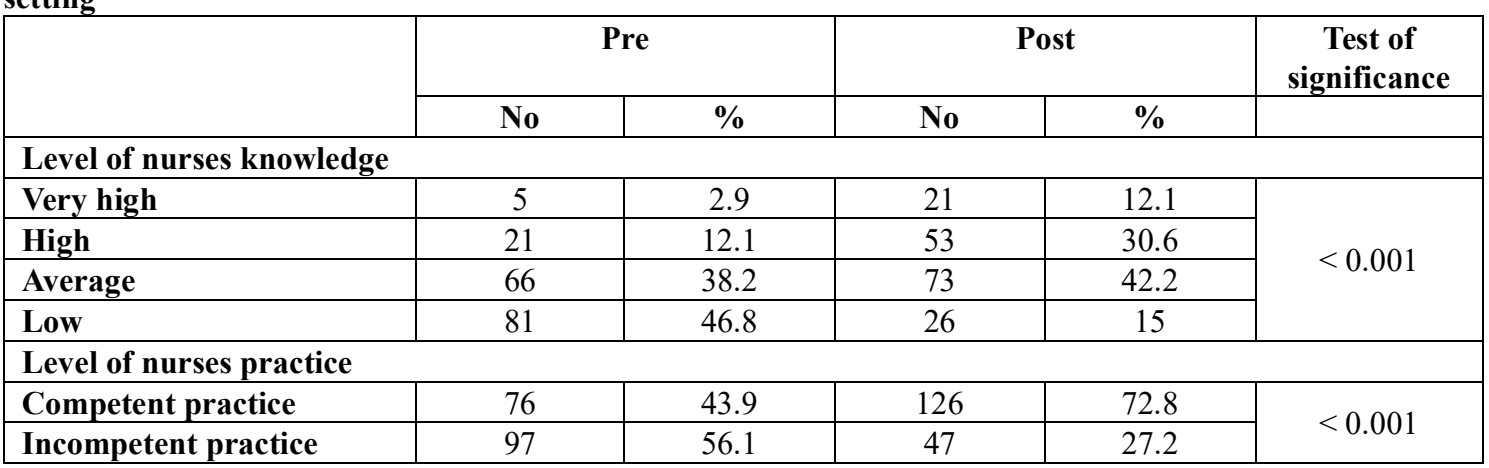

It was clear from table (3) that, there was a statistical significant difference in relation to total nurses' knowledge \& practice about safety measures in environmental health care setting pre and post program implementation $(\mathrm{P}<0.000)$. It was noted that, most of nurses had low level of knowledge and incompetent practice pre program $(46.8 \% \& 56.1 \%$ respectively). While, approximately three quarter of them $(72.8 \%)$ achieved competent practice post program.

Table (3); Pediatric nurses' perception of safety in health care environment

\begin{tabular}{|cl|c|}
\hline \multicolumn{1}{|c|}{ Variable } & Mean \pm SD \\
\hline 1. & Nurses Protection from health hazards are the first priority of hospital management & $2.16 \pm 1.2$ \\
\hline 2. & Within the department \& units; all necessary action are taken to reduce the risk & $1.84 \pm 0.9$ \\
\hline 3. & Nurses are encouraged to participate in the peace and health procedures & $1.93 \pm 1.1$ \\
\hline 4. & Nurses have enough time work to follow how to prevent risk & $2.37 \pm 1.19$ \\
\hline 5. & Work duties often do not interfere with being able to follow the precautions to be taken to reduce risk & $2.16 \pm 1.02$ \\
\hline 6. & Within the department or unit; all wrong practices are corrected by the head of the unit or supervisor & $1.9 \pm 1.02$ \\
\hline 7. & Safe practices within the hospital are taught by the department supervisor & $2.01 \pm 1.03$ \\
\hline 8. & In your workplace; you can access policies and regulations related to the safety of employees & $2.01 \pm 1.05$ \\
\hline 9. & $\begin{array}{l}\text { In your workplace; there is a connection between the department supervisor and the department } \\
\text { members }\end{array}$ & $1.92 \pm .98$ \\
\hline 10. & Unit workers support each other & $1.84 \pm 1.01$ \\
\hline
\end{tabular}

Table (4) illustrated nurses perception about safety in the health care environment; it was clear that, the nurses were disagree with the statements related to action taken to reduce the risks, the nurses are encouraged to participate in the peace and health procedures \& the support between the unit worker with the mean $(1.84 \pm 0.9$, $1.93 \pm 1.1 \& 1.84 \pm 1.01$ respectively).

\section{Discussion}

Hospitals are the most common high risk workplace characterized by higher level of exposure to hazardous agents, which dramatically endangers the health and peace of the health care worker especially nurses (Arazoo et al., 2015 and Abidoye et al., 2016). Many studies have indicated the need to identify \& evaluate hazards associated with nursing profession, as well as preventive measures to overcome the hazards and improve health and safety of nurses (Shimizu, et al., 2010). The study was conducted to investigate the effect of implementing nursing guidelines on occupational hazards and safety of pediatric nurses on the health care environment and to represent the most common hazards the nurses exposed during their working years.

The study found that the levels of physical, chemical \& biological hazards as reported by nurses working in MUCHs were critical. While, social \& emotional hazards level were tolerable. Regarding physical hazards, the current study illustrated that the most common physical hazard encountered by nurses was fatigue and it was highest problem as it was reported by more than three quarters $(77.9 \%)$ of nurses. Since for most procedures the nurses are standing for long time in providing different care for pediatric patient as (feeding, bathing, lifting, medication, blood sampling and moving patient from one place to another for further diagnostic procedure) and this is consequently becomes a burden on nurses health. In addition, more than half of nurses reported that they having back pain \& leg pain (Figure 1). This result may be due to long working hours per shift, standing long time during providing the patient care and shortage of nursing staff members. This result was in an agreement with the 
study achieved by Shimizu, et al., (2010) who explained that, neck pain and back pain were major workplace health problem and illustrated a huge burden on nursing staff members. Similarly Sreekala (2010), reported in his study that, the majority of nurses having varicose vein.

In relation to chemical \& biological hazards, this study clarified that, the most hazards facing nurses in their workplace were needle stick injury followed by MARS infection. This was in an agreement with Almurr, (2013); Bhargava et al. (2013) and Eljedi (2015), who revealed in a similar study that, the prevalence of sharp injuries were high. Concerning to nurses' social \& emotional hazards exposure, more than one third of nurses suffered from sadness \& easy excitability as in (Figure 2). This result may be attributed to that the nurses are overwhelming by hard work and caring for critical patient and patients with terminal illness and dying patient which in turn influencing on nurses social and emotional state \& shortage of nursing staff. Moreover, in the public hospital in the Federal District, a study conducted by Shimizu, et al., (2010) revealed that, the occurrence of physical hazards for nurses working at intensive care units were serious at a single Brazilian institution; while, the psychological and social hazard levels were reasonable. Moreover, the study results in Gaza, by Eljedi, (2015) indicated that, exposure to psychological hazards was high within all occupational hazards for nursing students.

The majority of the studied nurses reported that work overload, standing for long period of time \& lack of lifting tools for patients' transportation were considered the main predisposing factors for hazards in health care setting. Similarly, Abou El-enein and El Mahdy (2011) confirmed that the factors and barriers that influenced safety practice measures and that interfere with the safe practice of care was the high work load or lack and inaccessibility of sinks.

In spite of higher prevalence of nurses self-reported workplace hazards; we found limited knowledge about hazards among nurses, with approximately half of nurses had poor knowledge about prevention hazards in health care environment. Finally the study demonstrated the effect of educational intervention in improving nurses' knowledge and practice as it was reported in table (3) that there was a statistical significant difference pre/post implementing nursing guidelines about hazards prevention. This result was in an agreement with Galal, et al., (2014), Al Yousef, (2014) \& Stephenie, (2015) who found that higher level of knowledge towards standard safety measures, and infection control practices in the post intervention phase as compared with the pre intervention phase. Similarly, Victor et al., (2017) reported in his study about "effect of in-service education workshop on occupational health and safety in terms of knowledge and awareness among nurses in a selected tertiary care hospital in India: an evaluation" that, the program was effective in improving the knowledge and awareness of nurses regarding occupational health and safety.

\section{Limitation of the study}

The limitation of the study was that, the effect of the occupational hazard prevention \& safety program evaluate the nurses knowledge, practice and perception; while, the prevalence of hazards not evaluated after the implementation of the program. Moreover, the prevalence of hazards represented in the study was nurses' selfreported and not recorded incidence in the hospital.

\section{Conclusion \& Recommendation}

The study concluded that, the hazards associated with nursing profession were higher and critical. Many of these hazards are avoidable \& preventable and others are inevitable. From the study $77.9 \%$ of nurses suffered from fatigue, $69.5 \%$ of nurses had back pain. In addition, significant number of nurses are exposed to MRSA infection (61.7\%) and $67.4 \%$ are exposed to needle stick injury. In addition, the nurses' knowledge and practice was significantly improved after implementation of the occupational hazards and safety nursing guidelines. The researchers recommended developing recording \& reporting system for hazards facing health care worker especially nurses to improve their safety and commitment to the health care setting. Developing standard of health care safety clarifying the role of health care institution in dealing with and overcoming the occupational hazards in the health care setting. Regular physical examination must be done annually and at time of infection outbreak for all health care workers. Further researches are required to investigate factors affecting reporting of workplace hazards and why nursing staff continue to work after their affection with occupational hazard.

\section{Conflicts of interest disclosure}

The authors declare that there is no conflict of interest. 


\section{References}

Abou El-enein, N. and El Mahdy, H., (2011). Standard precautions: a KAP study among nurses in the dialysis unit in a University Hospital in Alexandria, Egypt. Journal of Egyptian Public Health Association, 86, pp.3-10.

Adelosoye, A., Adejumo, O., Akinbodewa, A., and Osungbemiro, B., (2016).Assessment of Occupational Health Safety and Hazard among Government Health Workers in Ondo City, Southwest Nigeria. British Journal of Medicine \& Medical Research, 13 (8): 1-8. Available at: www.sciencedomain.org

Al Yousef, S.A. (2014). Effect of Nursing Guidelines Regarding Infection Control Measures on Performance of Internship Students in Applied Medical Science College. JNHS 3: 37-46.

Almurr, B.,( 2013). Knowledge and Practice of Standard Precaution and Sharp Injures among Nurses in the Northern West Bank Hospitals ; Palestine, An-Najah National University Faculty of Graduate Studies This Thesis is Submitted in Partial Fulfillment of the Requirements for the Degree of Master of Public Health, Faculty of Graduate studies ,An-Najah National University, Nablus,Palestine. 2013. https://hdl.handle.net/20.500.11888/7825

Aluko, O. O., Adebayo, A. E., Adebisi, T. F., Ewegbemi, M. K., Abidoye, A. T., \& Popoola, B.F.(2016). Knowledge, attitudes and perceptions of occupational hazards and safety practices in Nigerian healthcare workers. BMC research notes, $9(1), 71$.

Anandh , B., Jayachandran, P., Josephin, D., Kalpana,B., Senthil, A., Thangavel ,G., Yamini, R.. (2015). Perception and prevalence of work-related health hazards among health care workers in public health facilities in southern India. International journal of occupational and environmental health, 21(1), 7481 .

Arazoo, A.., Bhatt, A, Butola, H., Painuly, D., Prasuna, J., Sharma, R., and Yadav, A. (2015). Occurrence and knowledge about needle stick injury in nursing students. Journal of Ayub Medical College Abbottabad, 27(2), 430-433.

Awan. A., Afzal. M., Majeed. I., Waqas. A.,Gilani.S.(2017).Assessment of Knowledge, Attitude and Practices regarding Occupational Hazards among Nurses 1.; Saudi J. Med. Pharm. Sci.; Vol-3, Iss-6B (Jun, 2017):622-630.Available Online: http://scholarsmepub.com/sjmps/

Bhargava A, Mishra B., Thakur A., Dogra, V., and Loomba, P., (2013): Assessment of knowledge, attitude and practices among healthcare workers in a tertiary care hospital on needle stick injury. Int J Health Care Qual Assur., 26(6):549-58. https://doi.org/10.1108/IJHCQA-04-2012-0035

Doyle, M. J. (2017). Allergic rhinitis. Dermatological Nursing. Mar2017, Vol. 16, Issue 1, p27-31. 5p. 3 Color Photographs.

Eljedi, A., (2015). Prevalence and Response to Occupational Hazards among Nursing Students in Gaza Strip, Palestine: The Role of Personal Protective Equipment and Safety Regulations. Public Health Research 2015, 5(1): 32-38.

Faremi, F. A., Ogunfowokan, A. A., Mbada, C., Olatubi, M. I., \&Ogungbemi, A. V. (2014). Occupational hazard awareness and safety practices among Nigerian sawmill workers. International journal of medical science and public health, 3(10), 1244-1249.

Galal, Y.S., Labib, J.R., Abouelhamd, W.A. (2014). Impact of an infection-control program on nurses' knowledge and attitude in pediatric intensive care units at Cairo University hospitals. J Egypt Public Health Assoc 89: 22-28.

Gao, J., (2011). An Investigation of the Impact of Operating Room Occupational Hazards on Intraoperative Nurses. Bachelor's Thesis. Degree Programme in Nursing School of Health and Social Studies. Jamk University of Applied Science.

Gorman, T., Dropkin, J., Kamen, J., Nimbalkar, S., Zuckerman, N., Lowe, T., \& Freund, A. (2014). Controlling health hazards to hospital workers: A reference guide. NEW SOLUTIONS: A Journal of Environmental and Occupational Health Policy, 23(1_suppl), 1-169.

Isara, A. R., \&Ofili, A. N. (2012).Prevalence of occupational accidents/Injuries among health care workers in a federal medical centre in southern Nigeria, . West African journal of medicine, 31(1), 47-51.

Osborne, S., (2002). Compliance with Standard Precautions and Occupational Exposure Reporting among Operating Room Nurses in Australia. A thesis submitted in fulfillment of the requirements for the degree of Master of Nursing by Research Division of Science and Design School of Nursing University of Canberra, March 2002.

Registered Nurses' Association of Ontario (2008). Workplace Health, Safety and Well-being of the Nurse. Toronto, Canada: Registered Nurses' Association of Ontario. 
Rhule, H. K. A. (2012). Health Related Risks of Nursing Practice at Effia-Nkwanta Regional Hospital, Sekondi. A Thesis submitted to Department of Theoretical and Applied Biology, Kwame Nkrumah University of Science and Technology in partial fulfillment of the requirements for the degree of Master of Science, June-2012.

Rogers, B.E.(2003). Occupational and Environmental Health Nursing, Concepts and Practice, $2^{\text {nd }}$ ed.; Saunders: Philadelphia, PA, USA.

Sarafis, P., Rousaki, E., Tsounis, A., Malliarou, M., Lahana, L., Bamidis, P., \& Papastavrou, E. (2016). The impact of occupational stress on nursese caring behaviors and their health related quality of life. $B M C$ nursing, 15(1), 56. https://doi.org/10.1186/s12912-016-0178-y

Sedlak, C. (September 30, 2004). "Overview and Summary: Nurse Safety: Have We Addressed the Risks?" Online Journal of Issues in Nursing. Vol. 9 No. 3, Overview and Summary. Available:www.nursingworld.org/MainMenuCategories/ANAMarketplace/ANAPeriodicals/OJIN/Tab leofContents/Volume92004/No3Sept04/NurseSafetyOverview.aspx

Shimizu, H. E., Couto, D. T., Merchán-Hamann, E., \& Branco, A. B. (2010). Occupational health hazards in ICU nursing staff. Nursing research and practice, Volume 2010, Article ID 849169, 6 page. http://dx.doi.org/10.1155/2010/849169

Smith RA. (2009). what you don't know can hurt you: Health hazards in the work environment. Journal of Perianesthesia Nursing.2009; 24(2):75-80. https://doi.org/10.1016/j.jopan.2008.11.005

Sreekala, K. (2010). A study to assess the prevalence and preventive practices of health problems and hazards among neuro nurses in SCTIMST. Nursing Education http://dspace.sctimst.ac.in/jspui/handle/123456789/1579

Stephanie, A (2015). The effectiveness of educational programs to improve the knowledge and compliance of healthcare workers towards standard precautions. The University of Hong Kong: 40-45.

Tung, C. Y., Chang, C. C., Ming, J. L., \& Chao, K. P. (2014). Occupational hazards education for nursing staff through web-based learning. International journal of environmental research and public health, 11(12), 13035-13046.

Victor, E. M., Joshi, P., Vasanth, E. M., \& Raghavan, S. (2017). Effect of In-Service Education Workshop on Occupational Health and Safety In Terms of Knowledge and Awareness among Nurses in a Selected Tertiary Care Hospital in India: An Evaluation. Journal of Nursing \& Patient Care, 2016.

Work Health and Safety Essentials for Nurses and Midwives. (2013). Published by the NSW Nurses and Midwives' Association. This work is funded under the Work Cover NSW Work Cover Assist Program. COPYRIGHT C2013 Work Cover NSW.

Zolot, J. (2017). Nurse Perception of Workplace Safety Affects Patient Care. AJN The American Journal of Nursing, 117(2), 14. 